\title{
USO DE DILUENTES E TEMPERATURAS ALTERNATIVAS NA CONSERVAÇÃO PROLONGADA DO SÊMEN DO VARRÃO
}

\section{USE OF ALTERNATIVE EXTENDERS AND TEMPERATURES IN LONG TERM STORAGE OF BOAR SEMEN}

\author{
Lina Raquel Santos Araújo1 \\ Tatyane Bandeira Barros ${ }^{1}$ \\ Daianny Barboza Guimarães ${ }^{1}$ \\ Ludymila Furtado Cantanhêde ${ }^{1}$ \\ Aline Viana Dias ${ }^{1}$ \\ Ricardo Toniolli2*
}

${ }^{1}$ Programa de Pós Graduação em Ciências Veterinárias da Faculdade de Veterinária da Universidade Estadual do Ceará, Fortaleza, CE, Brasil.

2 Laboratório de Reprodução Suína e Tecnologia de Sêmen da Faculdade de Veterinária da Universidade Estadual do Ceará, Fortaleza, CE, Brasil.

*Autor para correspondência - ricardo.toniolli@uece.br

\section{Resumo}

O uso de diluentes adequados é importante para o sucesso de um programa de inseminação artificial. O objetivo deste experimento foi avaliar a eficiência de diluentes alternativos para o sêmen suíno, em diferentes temperaturas $\left(17\right.$ e $\left.10^{\circ} \mathrm{C}\right)$. Foram utilizados os diluentes: Beltsville Thawing Solution (BTS); água de coco em pó (ACP $\left.{ }^{\circledR}-103\right)$ e leite em pó desnatado (LPD). Os 50 ejaculados, foram analisados in natura e após diluição, diariamente, durante os 5 dias de conservação do sêmen (D0 a D4), quanto ao vigor e motilidade espermática. Avaliou-se a integridade do acrossoma e a viabilidade espermática no D0 e D4. Na análise estatística, foram utilizados os testes de Mann-Whitney, Students, Tukey e o qui-quadrado, com intervalo de confiança de 5\%. O diluente LPD a $10{ }^{\circ} \mathrm{C}$ apresentou motilidade e vigor espermático melhores em relação ao BTS e ACP $\left(10^{\circ} \mathrm{C}\right)$ até $\mathrm{D} 2$ e aos tratamentos conservados a $17^{\circ} \mathrm{C}$. A vitalidade e integridade acrossomal, no D0 e D4, foram melhores com LPD a $10{ }^{\circ} \mathrm{C}$, que mostrou ser um bom meio diluente para o sêmen suíno em temperatura mais baixa (10 ${ }^{\circ} \mathrm{C}$ ), conferindo uma maior proteção à célula espermática, através de maiores taxas de viabilidade e integridade de acrossoma.

Palavras-chave: água de coco; conservação; leite desnatado; sêmen; varrão.

\begin{abstract}
The use of appropriate extenders is important for the success of an artificial insemination program. The objective of this study was to evaluate the efficiency of alternative extenders for swine semen at different temperatures $\left(17\right.$ to $\left.10^{\circ} \mathrm{C}\right)$. The following extenders were used: Beltsville Thawing Solution (BTS), powdered coconut water (ACP-103 ${ }^{\circledR}$ ), and skimmed milk powder (LPD). The 50 ejaculates were analyzed daily, in natura and after dilution, during the 5-day period of semen preservation (D0 to D4), regarding spermatic vigor and motility. Acrosome integrity and sperm viability were evaluated on D0 and D4. Data were analyzed using Mann-Whitney, Students, Tukey and chi-square tests $(\mathrm{p}<0.05)$. The LPD extender at $10{ }^{\circ} \mathrm{C}$ presented higher motility and sperm vigor compared to BTS and ACP until D2, and to treatments stored at $17^{\circ} \mathrm{C}$. Acrosome vitality and integrity remained higher $(\mathrm{p}<0.001)$ with LPD at $10^{\circ} \mathrm{C}$ on D0 and D4. LPD showed to be a good extender for the swine
\end{abstract}


semen at lower temperature $\left(10{ }^{\circ} \mathrm{C}\right)$. Furthermore, it provided better protection to sperm cells, by allowing greater integrity and vitality of the acrosome.

Keywords: coconut water; conservation; skimmed milk; semen boar.

Enviado em: 09 junho 2012

Aceito em: 27 outubro 2015

\section{Introdução}

O processamento do sêmen utilizando diluentes com composições adequadas e que proporcionem melhores condições de armazenagem é um dos pontos importantes para o sucesso de um programa de inseminação ${ }^{(1)}$. O uso de diluentes no preparo das doses de sêmen tem como finalidade aumentar o volume, proteger a célula contra o choque térmico, fornecer substratos necessários ao metabolismo espermático, estabilizar o $\mathrm{pH}$, inibir o crescimento bacteriano e manter o espermatozoide viável até o momento de ser introduzido no genital da fêmea ${ }^{(2)}$.

O sêmen suíno é o mais sensível às flutuações de temperatura e uma queda abaixo dos $15{ }^{\circ} \mathrm{C}$ pode causar choque térmico, com lesões irreversíveis na estrutura das células e perda de sua motilidade ${ }^{(3)}$, da permeabilidade seletiva e da integridade da membrana plasmática do espermatozoide, o que pode levar à sua morte ${ }^{(4)}$. A viabilidade do sêmen suíno mantém-se satisfatória durante 72 horas, à temperatura de $16{ }^{\circ} \mathrm{C}$, em diferentes diluentes comerciais (BTS, Kiew, Androhep, Reading, MR-A) até então utilizados ${ }^{(5)}$, sendo esse período insuficiente para um bom aproveitamento dos reprodutores. A procura por novos diluentes, para o sêmen de diferentes espécies domésticas levou pesquisadores a estudarem a água de coco em pó ${ }^{(6-8)}$ e o leite desnatado ${ }^{(9,10)}$ como alternativas viáveis na substituição dos tradicionais diluentes.

Deste modo, um diluente que permita um maior período de conservação do ejaculado é importante para o sucesso dos resultados da inseminação artificial ${ }^{(11)}$. Assim, faz-se necessário o desenvolvimento de técnicas e soluções que permitam a utilização do sêmen resfriado, sem queda dos resultados de fertilidade em particular na espécie suína ${ }^{(12,7)}$. O objetivo deste experimento foi avaliar a eficiência de diluentes alternativos para sêmen suíno, conservado em diferentes temperaturas.

\section{Material e Métodos}

O projeto de pesquisa foi aprovado pelo Comitê de Ética da Universidade Estadual do Ceará, em 29 de setembro de 2011, segundo processo $\mathrm{n}^{\circ} 11223066-0 / 48$, tendo atendido aos critérios solicitados pelo CEUA-UECE.

O sêmen de cinco reprodutores, sendo um de raça pura (Landrace) e quatro de reprodutores híbridos comerciais (Dalland e Agroceres Pic) foi coletado uma vez por semana, durante dez semanas ( $\mathrm{n}=$ 50), por meio da técnica da mão enluvada, em recipiente coberto por filtro e protegido por copo térmico, segundo Hancock e Hovell ${ }^{(13)}$. Presença de odor fétido ou urinoso indicam contaminação do ejaculado, o que levou ao descare do material. Antes de cada coleta, foi realizada uma higienização externa do prepúcio, seguida de esgotamento prepucial no sentido caudo-cranial por pressão manual. O ejaculado total foi coletado em recipiente coberto com gaze, com capacidade de $500 \mathrm{~mL}$, e protegido por envoltório térmico. A fração gelatinosa, retida pela gaze era desprezada. Os machos utilizados no experimento se encontravam em sistema rotineiro de coleta semanal. Foram utilizados animais com idades variando entre 12 e 24 meses, pertencentes ao Laboratório de Reprodução Suína e Tecnologia do Sêmen (LRSTS) da FAVET/UECE.

Os animais eram alimentados com ração balanceada de boa qualidade, com níveis proteicos, energéticos e minerais dentro dos padrões estipulados para reprodutores em sistema de trabalho (3.150 Kcal e $14 \%$ de PB; $2,5 \mathrm{Kg}$ /dia em dois arraçoamentos). Água potável era fornecida ad libitum. Logo após a coleta, o ejaculado identificado foi levado ao laboratório para o seu processamento, mantendo-se o copo de coleta dentro da proteção térmica. Agaze foi retirada e descartada juntamente com 
a fração gelatinosa retida. A qualidade do sêmen in natura foi avaliada pelas seguintes características: volume $(\mathrm{mL})$ em balança digital com tara; concentração $\left(\mathrm{x} 10^{6} \mathrm{sptz} / \mathrm{mL}\right)$ em espectrofotômetro; total de espermatozoides $\left(\mathrm{x} 10^{9} \mathrm{sptz}\right)$, multiplicando-se o resultado de concentração pelo volume; vigor espermático (0 a 5), conforme descrito por Toniolli ${ }^{(14)}$; e motilidade espermática ( 0 a $\left.100 \%\right)$, conforme descrita por Martin Rillo ${ }^{(15)}$. Para as duas últimas características, uma amostra do sêmen $(15 \mu \mathrm{L})$ foi colocada entre lâmina e lamínula e feita a leitura em microscopia óptica com um aumento de 200 vezes. Foram avaliados para cada característica no mínino três campos de microscópio. As análises serviram para avaliação e controle de cada ejaculado durante o período experimental, foram feitas sempre pela mesma pessoa e somente os ejaculados que apresentassem valores de $\geq 3,0$ para o vigor e $\geq 80 \%$ de motilidade eram utilizados.

Após estas primeiras avaliações, o sêmen foi colocado em banho-maria a $30{ }^{\circ} \mathrm{C}$ durante 15 minutos, para, em seguida, ser diluído de acordo com os tratamentos experimentais, dentro da primeira meia hora pós coleta. Sêmen e diluente se encontravam sempre à mesma temperatura. Um total de 2,63 x $10^{9} \mathrm{sptz}$ foi separado de cada ejaculado e repartido equitativamente entre os seis tratamentos (três diluentes $\mathrm{x}$ duas temperatura de conservação). $\mathrm{O}$ sêmen diluído foi mantido a uma concentração fixa de $35 \times 10^{6} \mathrm{sptz} / \mathrm{mL}$, com um volume final por tratamento de 12,5 $\mathrm{mL}$ (sêmen + diluente), envasados em cinco tubos de ensaio/tratamento $\left(2,5 \mathrm{~mL} /\right.$ tubo $\left.=87,5 \times 10^{6} \mathrm{sptz} / \mathrm{tubo}\right)$.

Foram testados três diluentes de sêmen diferentes: Beltsville Thawing Solution (BTS - controle); diluente água de coco em pó $\left(\mathrm{ACP}-103^{\circledR}\right)$, oriundo da desidratação da água de coco in natura, pela técnica do spray dry ${ }^{(16)}$, foi reconstituído com água destilada nas seguintes proporções: $24 \mathrm{~g}$ de ACP + $100 \mathrm{~mL}$ de água destilada + sulfato de gentamicina a $80 \mathrm{mg} / 100 \mathrm{~mL}$; e leite em pó desnatado (LPD), diluído em água destilada nas seguintes proporções: $10 \mathrm{~g}$ de LPD $+0,194 \mathrm{~g}$ glicose $+100 \mathrm{~mL}$ de água destilada + sulfato de gentamicina a $80 \mathrm{mg} / 100 \mathrm{~mL}$. Cada $100 \mathrm{~g}$ de LPD foi composta por: carboidratos (56 g); proteínas (20,8 g); fibra solúvel (9,6 g); sódio (300 mg); cálcio (2 g); ferro (17,2 $\mathrm{mg})$; vitaminas A $(564 \mu \mathrm{g}), \mathrm{D}(6 \mu \mathrm{g}), \mathrm{E}(18,8 \mathrm{mg})$ e C (92 mg) e ácido fólico (480 $\mu \mathrm{g})$, segundo o fabricante.

$\mathrm{O}$ sêmen diluído a $30{ }^{\circ} \mathrm{C}$ foi submetido à duas temperaturas de conservação, 17 e $10^{\circ} \mathrm{C}$. Após a diluição e envaze nos tubos de ensaio, o sêmen foi colocado em geladeira a $17^{\circ} \mathrm{C}$. Os tubos de ensaio referentes às amostras que seriam conservadas a $10^{\circ} \mathrm{C}$, permaneceram inicialmente estocados a $17^{\circ} \mathrm{C}$ por 1 hora, para em seguida serem transferidos para outra geladeira com temperatura de conservação de $10^{\circ} \mathrm{C}$.

O sêmen foi conservado durante um total de cinco dias, sendo o dia da coleta considerado como dia zero (D0) e permanecendo por mais quatro dias: D0, D1, D2, D3 e D4.

A cada dia de análise, os tubos equivalentes a cada ejaculado/tratamento foram retirados das geladeiras e, em seguida, levados ao banho-maria a $39^{\circ} \mathrm{C}$ e incubados por 10 minutos, para em seguida serem analisados conforme as características abaixo:

a) Vigor e motilidade espermática: visando à avaliação da qualidade espermática, foi analisado o vigor espermático ( 0 a 5), segundo Toniolli(14), e a motilidade espermática (\% células móveis), segundo Martin Rillo ${ }^{(15)}$, colocando-se uma gota de sêmen de $15 \mu \mathrm{L}$ entre lâmina e lamínula, com leitura em microscopia óptica a um aumento de 200 vezes. Para estas características, o sêmen diluído e conservado foi analisado diariamente durante todo período de conservação (D0, D1, D2, D3 e D4). b) Integridade acrossomal e vitalidade espermática: visando às análises morfológicas acrossomal e de vitalidade espermática (\% sptz vivos), esfregaços de sêmen foram feitos no primeiro dia (D0, após 6 horas de conservação - Exame 1) e no último dia de conservação do sêmen (D4 - Exame 2). Em ambos os momentos, o esfregaço foi feito após os tubos de ensaio contendo sêmen terem sido retirados das geladeiras e reaquecidos a $39^{\circ} \mathrm{C}$ durante 10 minutos. Os esfregaços foram corados pela solução corante vital de azul de bromofenol $(0,1 \mathrm{~g}$; citrato de sódio $=0,4 \mathrm{~g}$; água destilada $=10 \mathrm{~mL}$ ), conforme descrito por Medeiros et al. ${ }^{(17)}$, visando identificar e separar as células vivas das mortas. Foram contadas 200 células por esfregaço corado, em microscopia óptica com lente de imersão (aumento 1000x). Juntou-se uma gota de sêmen com outra de corante sendo, em seguida, homogeneizada e permanecendo assim durante 30 segundos. Depois disso, procedeu-se ao esfregaço húmido, o qual ficou em cima da bancada à temperatura ambiente $\left(25^{\circ} \mathrm{C}\right)$ até secar. Para fim de análises, os espermatozoides foram classificados em quatro categorias: 1) vivos com acrossoma intacto; 2) vivos com acrossoma danificado; 3) mortos com acrossoma intacto; 4) mortos com 
acrossoma danificado ${ }^{(2)}$.

O delineamento experimental utilizado foi o de Blocos ao Acaso. A análise estatística foi feita por meio da avaliação das médias e desvios-padrão, aos quais foram aplicados testes de análise de variância. As variáveis quantitativas foram avaliadas quanto à normalidade de sua distribuição utilizando-se o teste de Shapiro-Wilk. A análise das diferenças entre médias foi realizada por meio de uma variância multifatorial usando-se o General Linear Models (GLM) do programa Statistical Analysis System (SAS 8, 2002). Os testes estatísticos propostos foram: Mann Whitney (variáveis não paramétricas), Students e Tukey (variáveis paramétricas), para a comparação entre grupos, e o teste do Qui-quadrado corrigido (apenas para características expressas em porcentagem). Para a significância estatística, foi utilizado um intervalo de confiança de $\mathrm{p}<0,05$ (nível de significância de 5\%). Cada animal representou uma unidade experimental, com o número de ejaculados correspondendo ao número de repetições do experimento. Foi prevista a possibilidade de uma análise com um número diferente de repetições por variável a ser estudada.

\section{Resultados e Discussão}

O sêmen in natura proveniente de 50 ejaculados analisados durante o experimento apresentou aspecto normal, coloração branca leitosa, volume médio de $255,0 \pm 52 \mathrm{~mL}$ e concentração média de $393,4 \pm 26$ x $10^{6} \mathrm{sptz} / \mathrm{mL}$. Tais características estão dentro da normalidade para a espécie suína ${ }^{(1,18)}$. A análise do vigor espermático $(4,0 \pm 0,4)$ e da motilidade espermática $(91,0 \% \pm 6,2)$ apresentaram valores do ejaculado in natura acima dos critérios de exclusão estipulados pela metodologia para utilização do ejaculado.

Das amostras conservadas a $17^{\circ} \mathrm{C}$, o LPD apresentou melhores resultados de vigor espermático $(3,2 \pm 1,0)$ em relação ao $\operatorname{BTS}(2,3 \pm 1,0)$ e ao $\operatorname{ACP}(2,3 \pm 0,9)$ apenas no D0 e em relação ao BTS no D1 $(\mathrm{p}<0,05)$. Por outro lado, nos demais dias de conservação, o BTS apresentou melhores valores para essa característica em relação ao LPD e ao ACP, os quais apresentaram resultados ruins e similares, aproximando-se de zero a partir do terceiro dia de conservação (D2). Durante o período de conservação, a queda dos valores do vigor espermático foi mais acentuada nos diluentes ACP e LPD (Tabela 1).

A baixa performance do ACP a $17{ }^{\circ} \mathrm{C}$ a partir do D2 divergiu dos resultados obtidos por outros autores ${ }^{(10)}$, que encontraram valores para o vigor espermático superiores aos do BTS até o quarto dia de conservação (D3); entretanto, sem diferenças em D0. Embora a literatura já apresente bons resultados de vigor espermático com a utilização do ACP na preservação do sêmen de diversas espécies domésticas, tais como caprinos ${ }^{(6)}, \operatorname{caninos}^{(19)}$ ovinos $^{(20)}$, capote $^{(21)}$ e suínos $^{(10)}$, neste estudo, não se repetiu o mesmo bom desempenho. Aqui ele só manteve bom vigor espermático até o segundo dia de conservação (D1); após esse período os valores sofreram quedas significativas, ficando abaixo dos resultados do diluente BTS.

Tabela 1: Vigor espermático do sêmen suíno conservado durante 5 dias em diferentes temperaturas $\left(17\right.$ e $\left.10^{\circ} \mathrm{C}\right)$ nos diluentes BTS, ACP-103 ${ }^{\circ}$ e LPD

\begin{tabular}{|c|c|c|c|c|c|c|}
\hline \multicolumn{2}{|c|}{ Tratamentos } & \multicolumn{5}{|c|}{ Dias de conservação } \\
\hline & & D0 & D1 & D2 & D3 & D4 \\
\hline & BTS & $2,3 \pm 1,0^{\mathrm{a}}$ & $1,5 \pm 1,0^{\mathrm{a}}$ & $1,5 \pm 1,0^{\mathrm{ab}}$ & $1,3 \pm 1,0^{\mathrm{ab}}$ & $0,9 \pm 0,9^{\mathrm{a}}$ \\
\hline \multirow{2}{*}{$17^{\circ} \mathrm{C}$} & $\mathbf{A C P}$ & $2,3 \pm 0,9^{a}$ & $2,0 \pm 1,0^{b}$ & $0,6 \pm 0,9^{d}$ & $0,2 \pm 0,6^{c}$ & $0,1 \pm 0,5^{\mathrm{b}}$ \\
\hline & LPD & $3,2 \pm 1,0^{\mathrm{b}}$ & $1,9 \pm 1,1^{b}$ & $0,1 \pm 0,5^{\mathrm{c}}$ & $0,0 \pm 0,1^{\mathrm{c}}$ & $0,0 \pm 0,1^{b}$ \\
\hline \multirow{3}{*}{$10^{\circ} \mathrm{C}$} & BTS & $2,2 \pm 0,9^{a}$ & $1,4 \pm 1,1^{\mathrm{a}}$ & $1,0 \pm 1,0^{\mathrm{b}}$ & $1,0 \pm 1,0^{\mathrm{a}}$ & $0,8 \pm 1,0^{\mathrm{a}}$ \\
\hline & $\mathbf{A C P}$ & $2,2 \pm 1,0^{\mathrm{a}}$ & $1,7 \pm 1,2^{\mathrm{ab}}$ & $1,6 \pm 1,0^{\mathrm{a}}$ & $1,2 \pm 1,0^{\mathrm{ab}}$ & $0,9 \pm 0,9^{\mathrm{a}}$ \\
\hline & LPD & $3,1 \pm 1,1^{b}$ & $2,6 \pm 1,1^{\mathrm{c}}$ & $2,3 \pm 1,0^{\mathrm{e}}$ & $1,6 \pm 1,1^{b}$ & $1,1 \pm 1,1^{\mathrm{a}}$ \\
\hline
\end{tabular}

$a, b, c$ Letras diferentes na mesma coluna indicam diferenças estatisticamente significativas $(p<0,05)$. 
Quando o sêmen diluído foi conservado a $10{ }^{\circ} \mathrm{C}$, o LPD apresentou os melhores resultados para vigor espermático $(\mathrm{p}<0,01)$ até o terceiro dia de conservação (D2), indicando uma melhor capacidade de manutenção dessa característica em temperatura mais baixa, que normalmente provoca choque térmico $^{(4)}$ e tem uma ação deletéria sobre o espermatozoide. Mais uma vez, em todos os diluentes houve queda dos valores do vigor durante o período de conservação do sêmen; entretanto, a 10 ${ }^{\circ} \mathrm{C}$, esta queda foi menos acentuada no diluente LPD, com um valor de 2,3 $\pm 1,0$ em D2, em relação ao controle $(1,0 \pm 1,0)$, considerando-se que o diluente BTS é o diluente para o sêmen suíno mais utilizado em todo o mundo.

A utilização do diluente LPD, conservado em temperaturas mais baixas, apresentou os melhores resultados de vigor espermático ${ }^{(9)}$, sendo mesmo capaz de preservar melhor a motilidade espermática que outros diluentes ${ }^{(22)}$, particularmente quando comparado aos resultados do BTS ou do ACP. Desta forma, o LPD apresentou-se como uma boa opção, fornecendo uma melhor condição de sobrevivência para os espermatozoides em temperaturas mais baixas ${ }^{(23)}$, dispensando o uso de conservadores de sêmen suíno, que normalmente têm custos de aquisição mais altos.

Para a característica vigor, dentro de cada diluente, quando comparados os resultados nas duas temperaturas de conservação $\left(10\right.$ e $\left.17^{\circ} \mathrm{C}\right)$, não foram verificadas diferenças no sêmen diluído no BTS durante todo período de conservação. Para o ACP, uma mesma tendência foi observada apenas até o segundo dia de conservação e a partir de $\mathrm{D} 2$ os resultados a $10{ }^{\circ} \mathrm{C}$ foram melhores $(\mathrm{p}<0,05)$ até o final do período de conservação. Com o LPD já a partir do D1 os resultados a $10{ }^{\circ} \mathrm{C}$ foram sempre melhores do que a $17^{\circ} \mathrm{C}(\mathrm{p}<0,05)$, com uma queda brusca dos valores a partir de D2. Estes resultados demonstram claramente a boa ação conservadora do LPD sobre a célula espermática suína a $10^{\circ} \mathrm{C}$. O espermatozoide suíno é uma das células mais sensíveis ao frio ${ }^{(1)}$, tendo como temperatura ideal de conservação valores entre 15 e $18{ }^{\circ} \mathrm{C}$. Normalmente, a manutenção do sêmen suíno em temperatura abaixo de $15{ }^{\circ} \mathrm{C}$ permite o choque térmico, afetando de forma negativa o vigor espermático ${ }^{(4)}$. Contudo, neste estudo, não se verificou uma queda acentuada, devido provavelmente à uma melhor proteção contra o choque térmico, o que evidenciou uma melhor ação de proteção e conservação no meio à base de $\operatorname{LPD}^{(22)}$. Quando utilizado a $17{ }^{\circ} \mathrm{C}$, o LPD não apresentou uma boa ação, traduzida por uma pior qualidade espermática, resultando em deterioração celular, fato esse que pode ocorrer durante um armazenamento prolongado em temperaturas mais altas ${ }^{(24)}$. Tais alterações contribuíram para "coalhar" o leite, fato esse que ocorreu com frequência a partir do D2, piorando a qualidade espermática e dificultando a realização das análises. A possibilidade de utilização do LPD na diluição/ conservação do sêmen suíno a $17^{\circ} \mathrm{C}$, em vista dos resultados obtidos nesse trabalho, está condicionada a um melhor desenvolvimento do protocolo a ser utilizado, pois, a esta temperatura, ele só pode ser utilizado para inseminações sem conservação do sêmen.

Para a característica motilidade espermática a $17{ }^{\circ} \mathrm{C}$ (Tabela 2), o LPD apresentou resultados melhores $(\mathrm{p}<0,05)$ apenas no primeiro dia de conservação $(72,9 \%)$ em relação aos diluentes BTS e ACP (58,2\% e 54,2\%, respectivamente). Nesta temperatura, o BTS apresentou valores maiores particularmente nos três últimos dias de conservação $(p<0,05)$, justificando o fato de ser o diluente mais utilizado nos programas de inseminação artificial, também pela facilidade de fabricação e baixo preço de comercialização ${ }^{(25)}$. Estes resultados podem ser explicados pelo fato de o LPD não ser capaz de preservar o sêmen por um período prolongado de tempo, devido a um processo de deterioração de seus componentes ${ }^{(24)}$, particularmente em temperaturas mais altas $\left(17^{\circ} \mathrm{C}\right)$. Os resultados deste trabalho divergem do de estudos anteriores utilizando-se o ACP em relação ao BTS, nos quais evidenciaramse efeitos benéficos in vitro sobre a motilidade espermática ${ }^{(12,7)}$, com valores melhores durante todo $\mathrm{o}$ período de conservação ${ }^{(10)}$.

Comparando-se os resultados de motilidade a $17{ }^{\circ} \mathrm{C}$ (Tabela 2), com o ACP os valores caíram para $54,2 \%$ já no primeiro dia de conservação (D0), valor inferior ao obtido com o LPD (72,9\%). Os resultados deste trabalho discordam de estudos em pequenos ruminantes, em que melhores resultados foram obtidos com o ACP, com valores de motilidade maiores por até 48 horas em relação ao $\mathrm{LPD}^{(6)}$. Essas diferenças podem indicar uma melhor adaptação do diluente ligada à espécie animal. Possivelmente, a maior sensibilidade do espermatozoide suíno pode ter contribuído para essas 
diferenças de resultados de conservação entre as espécies em questão. O baixo desempenho do ACP na conservação da motilidade espermática também já foi evidenciado em trabalhos mais recentes, com resultados inferiores aos do presente estudo ${ }^{(26)}$, aparentemente não podendo ser indicado como diluente para o sêmen suíno.

Tabela 2: Total de espermatozoides móveis (\%) do sêmen suíno conservado durante 5 dias em diferentes temperaturas $\left(17\right.$ e $\left.10^{\circ} \mathrm{C}\right)$ nos diluentes BTS, ACP-103 ${ }^{\circledR}$ e LPD

\begin{tabular}{|c|c|c|c|c|c|c|}
\hline \multicolumn{2}{|c|}{ Tratamentos } & \multicolumn{5}{|c|}{ Dias de conservação } \\
\hline & & D0 & D1 & D2 & D3 & D4 \\
\hline \multirow{3}{*}{$17^{\circ} \mathrm{C}$} & BTS & $58,2 \pm 27^{b}$ & $36,0 \pm 28^{\mathrm{ab}}$ & $32,1 \pm 26^{a}$ & $26,5 \pm 24^{\mathrm{ac}}$ & $17,7 \pm 21^{\mathrm{a}}$ \\
\hline & $\mathbf{A C P}$ & $54,2 \pm 24^{\mathrm{ab}}$ & $44,4 \pm 25^{a}$ & $12,8 \pm 22^{b}$ & $3,9 \pm 13^{b}$ & $1,8 \pm 8,8^{b}$ \\
\hline & LPD & $72,9 \pm 28^{c}$ & $43,6 \pm 28^{a}$ & $2,7 \pm 10^{\mathrm{c}}$ & $0,1 \pm 0,7^{b}$ & $0,1 \pm 0,8^{b}$ \\
\hline \multirow{3}{*}{$10^{\circ} \mathrm{C}$} & BTS & $46,9 \pm 25^{\mathrm{a}}$ & $27,4 \pm 24^{b}$ & $20,1 \pm 23^{b}$ & $20,1 \pm 23^{\mathrm{a}}$ & $13,4 \pm 18^{\mathrm{a}}$ \\
\hline & $\mathbf{A C P}$ & $50,8 \pm 26^{\mathrm{ab}}$ & $36,1 \pm 28^{\mathrm{ab}}$ & $31,4 \pm 24^{a}$ & $27,3 \pm 24$ ac & $14,6 \pm 19^{a}$ \\
\hline & LPD & $73,8 \pm 26^{c}$ & $60,5 \pm 27^{c}$ & $50,2 \pm 26^{d}$ & $35,5 \pm 26^{c}$ & $20,5 \pm 23^{a}$ \\
\hline
\end{tabular}

$a, b, c$ Letras diferentes na mesma coluna indicam diferenças estatisticamente significativas $(p<0,05)$.

Na conservação a $10{ }^{\circ} \mathrm{C}$ (Tabela 2$)$, os resultados para esta característica foram melhores $(\mathrm{p}<0,01)$ com o uso do LPD durante praticamente todo o período de conservação (D0 a D3). O BTS e o ACP apresentaram resultados semelhantes durante todo o período de conservação, exceto em D2, quando o ACP foi melhor $(31,4 \%)$. Para o sêmen suíno, mais uma vez, o diluente LPD demonstrou ser um diluente mais adequado para a conservação da célula espermática do varrão em temperaturas mais baixas ${ }^{(22)}$, mantendo um maior percentual de células móveis em relação aos diluentes ACP e BTS conservados a $12{ }^{\circ} \mathrm{C}^{(23)}$. Discordando dos achados de Katzer et al. ${ }^{(26)}$, os resultados deste estudo com os diluentes ACP e BTS apresentaram valores menores que os preconizados para sua utilização em programas de inseminação artificial, durante todo o período de conservação do sêmen, não sendo então indicado o seu uso a esta temperatura.

O sêmen suíno diluído normalmente sofre uma queda acentuada da motilidade nas primeiras 12 horas de armazenamento, sendo mais pronunciada a $10{ }^{\circ} \mathrm{C}$, sugerindo que os espermatozoides são incapazes de se adaptar a temperaturas abaixo de $12{ }^{\circ} \mathrm{C}$, provavelmente devido a danos na membrana plasmática ${ }^{(28)}$. A queda dos valores dessa característica pode ser minimizada dependendo do diluente utilizado. Com o uso do LPD, os resultados obtidos comprovaram que um meio melhor adaptado às necessidades do espermatozoide suíno pode manter valores maiores de motilidade ${ }^{(22)}$.

Os resultados deste estudo com o uso do LPD, particularmente a $10{ }^{\circ} \mathrm{C}$, abriram uma nova perspectiva para a conservação do sêmen do varrão. O LPD é um diluente de fácil preparo, baixo custo, uso prático e efetiva ação de proteção ao espermatozoide durante sua conservação. Ele já foi usado por outros autores preservando a motilidade espermática, tanto no sêmen refrigerado quanto congelado ${ }^{(29)}$, sendo um fluído biológico de composição complexa, contendo componentes com ação benéfica para o gameta e podendo ser utilizado em diferentes processos biotecnológicos ${ }^{(30)}$.

Apesar dos resultados de vigor e motilidade terem sido oriundos de uma conservação prolongada do sêmen, o LPD apresentou-se como uma excelente opção, particularmente quando conservados a 10 ${ }^{\circ} \mathrm{C}$. Entretanto, em temperaturas mais altas $\left(17^{\circ} \mathrm{C}\right)$ em outras espécies, ele pode apresentar efeitos tóxicos à célula espermática, devido à presença de alguns de seus componentes ${ }^{(31,9)}$. De qualquer forma, trabalhos adicionais são necessários a fim de se estabelecer de forma mais precisa o limite de temperatura que não permita a produção desses componentes tóxicos no leite, bem como se verificar o desenvolvimento bacteriano. 
A porcentagem da vitalidade espermática em D0 foi significativamente maior no diluente LPD, quando comparada com os resultados obtidos com BTS e ACP ( $<<0,001)$, nas duas temperaturas (Tabela 3 ). Após o período de conservação, em D4 a $10{ }^{\circ} \mathrm{C}$, novamente o LPD apresentou o melhor resultado $(32,9 \pm 27,8)$; já a $17^{\circ} \mathrm{C}$, o BTS $(18,1 \%)$ apresentou uma maior porcentagem de espermatozoides vivos quando comparado aos demais diluentes $(\mathrm{p}<0,05)$. A forte queda da porcentagem de células vivas no LPD $(8,6 \%)$ e no ACP $(9,6 \%)$, ao final do período de conservação do sêmen, pode estar vinculada ao fato de esses diluentes serem ricos meios de conservação, associados a uma temperatura mais alta $\left(17^{\circ} \mathrm{C}\right)$, a uma menor diminuição do metabolismo celular e a uma maior possibilidade de desenvolvimento microbiano no meio de diluição/conservação ${ }^{(31,9)}$.

Por outro lado, a $10{ }^{\circ} \mathrm{C}$ o LPD apresentou uma maior porcentagem de células vivas $(\mathrm{p}<0,001)$, em relação aos outros diluentes, equivalendo-se apenas ao BTS no D4 ( $>00,05)$, apesar de um valor médio maior (32,9 e 19,7\%, respectivamente). A queda natural na porcentagem de células vivas é explicada pelas alterações de $\mathrm{pH}$ e osmolaridade do meio, mas que pode ser controlada pela qualidade do diluente, juntamente com a inibição do crescimento bacteriano durante o decorrer do tempo de conservação do sêmen ${ }^{(32)}$. Esta queda foi menos acentuada quando utilizado o diluente LPD $(59,29 \%)$ em relação ao BTS $(61,75 \%)$ e ao ACP (69,71\%), proporcionando um maior número de espermatozoides vivos ao final do período de conservação do sêmen e demonstrando ser esse diluente, à temperatura de $10^{\circ} \mathrm{C}$, melhor adaptado as necessidades de sobrevivência do espermatozoide suíno.

Tabela 3: Total de espermatozoides vivos (\%) do sêmen suíno, conservado durante 5 dias em diferentes temperaturas $\left(17\right.$ e $\left.10^{\circ} \mathrm{C}\right)$ nos diluentes BTS, ACP-103 ${ }^{\circledR}$ e LPD

\begin{tabular}{cccc}
\hline Temperaturas & Diluentes & \multicolumn{2}{c}{ Dias de conservação } \\
\hline & & D0 & D4 \\
\hline \multirow{2}{*}{$\mathbf{1 7}^{\circ} \mathbf{C}$} & BTS & $61,3 \pm 17,9^{\mathrm{a}}$ & $18,1 \pm 20,5^{\mathrm{a}}$ \\
& ACP & $56,2 \pm 16,6^{\mathrm{a}}$ & $9,6 \pm 13,4^{\mathrm{bc}}$ \\
& LPD & $81,2 \pm 16,0^{\mathrm{b}}$ & $8,6 \pm 13,4^{\mathrm{c}}$ \\
\hline \multirow{2}{*}{$\mathbf{1 0}^{\circ} \mathbf{C}$} & BTS & $51,5 \pm 17,6^{\mathrm{a}}$ & $19,7 \pm 21,9^{\mathrm{ad}}$ \\
& ACP & $51,5 \pm 17,0^{\mathrm{a}}$ & $15,6 \pm 15,6^{\mathrm{ab}}$ \\
& LPD & $80,8 \pm 19,6^{\mathrm{b}}$ & $32,9 \pm 27,8^{\mathrm{d}}$ \\
\hline
\end{tabular}

$a, b, c$ Letras diferentes na mesma coluna indicam diferenças estatisticamente significativas $(\mathrm{p}<0,001)$.

Conforme resultados apresentados na Tabela 4, o LPD manteve uma maior percentagem de células com acrossoma intacto em ambas as temperaturas $\left(10\right.$ e $\left.17^{\circ} \mathrm{C}\right)$ no $\mathrm{D} 0$, quando comparado aos demais diluentes $(\mathrm{p}<0,001)$. No último dia conservação, essa superioridade foi vista apenas a $10{ }^{\circ} \mathrm{C}(\mathrm{p}<0,01)$, demonstrando mais uma vez a boa ação deste diluente na conservação do sêmen suíno em temperaturas mais baixas. Comparando-se os outros dois diluentes (BTS e ACP), não foram observadas diferenças $(\mathrm{p}>0,05)$ para esta característica, nas duas temperaturas de conservação, discordando do observado por Toniolli et al. ${ }^{(10)}$, que verificaram uma maior porcentagem de células vivas com acrossoma íntegro em D4, no diluente ACP em relação ao BTS.

Neste estudo, a temperatura de conservação não afetou negativamente a porcentagem de células vivas com acrossoma íntegro, particularmente no LPD, discordando de outros estudos entre 5 e $12{ }^{\circ} \mathrm{C}$, com valores menores para o sêmen conservado a $17{ }^{\circ} \mathrm{C}^{(27)}$. Os melhores resultados encontrados no LPD, a $10{ }^{\circ} \mathrm{C}$, podem ser explicados pela presença das lipoproteínas e lecitinas do leite, que conferem uma proteção à célula espermática contra o choque térmico, quando adicionadas ao sêmen antes do 
resfriamento $^{(33)}$. Também há relatos na literatura sobre o efeito protetor do leite desnatado à célula espermática durante o processo de criopreservação ${ }^{(34)}$.

Tabela 4: Total de células com acrossoma intacto (\%) do sêmen suíno, conservado durante 5 dias em diferentes temperaturas $\left(17\right.$ e $\left.10^{\circ} \mathrm{C}\right)$ nos diluentes BTS, ACP-103 ${ }^{\circledR}$ e LPD

\begin{tabular}{clcc}
\hline Temperaturas & Diluentes & \multicolumn{2}{c}{ Dias de conservação } \\
\hline \multirow{2}{*}{$\mathbf{1 7}^{\circ} \mathbf{C}$} & D0 & D4 \\
& ACP & $87,2 \pm 9,2^{\mathrm{a}}$ & $80,8 \pm 9,7^{\mathrm{a}}$ \\
& $\mathbf{L P D}$ & $84,6 \pm 7,2^{\mathrm{a}}$ & $81,1 \pm 12,0^{\mathrm{a}}$ \\
\hline \multirow{2}{*}{$\mathbf{1 0}^{\circ} \mathbf{C}$} & $\mathbf{B T S}$ & $82,3 \pm 10,3 \pm 3,6^{\mathrm{b}}$ & $80,8 \pm 9,3^{\mathrm{a}}$ \\
& $\mathbf{A C P}$ & $86,3 \pm 8,0^{\mathrm{a}}$ & $74,1 \pm 15,4^{\mathrm{a}}$ \\
& LPD & $95,7 \pm 6,1^{\mathrm{b}}$ & $80,9 \pm 10,7^{\mathrm{a}}$ \\
\hline
\end{tabular}

$a, b, c$ Letras diferentes na mesma coluna indicam diferenças significativas $(\mathrm{p}<0,001)$.

\section{Conclusões}

O leite em pó desnatado (LPD) mostrou ser um bom meio diluente para o sêmen suíno em temperatura mais baixa $\left(10^{\circ} \mathrm{C}\right)$, possibilitando uma diminuição de custos de produção por não haver necessidade do uso de conservadores de sêmen que são sempre de aquisição mais cara do que geladeiras comuns, adaptadas com a instalação de termostatos mais sensíveis. Além disso, esse diluente conferiu uma maior proteção à célula espermática, em relação aos outros diluentes, proporcionando uma expectativa de melhores taxas de fertilidade quando sêmen é conservado dessa maneira.

\section{Agradecimentos}

À bolsa concedida pela Coordenação de Aperfeiçoamento de Pessoal de Nível Superior (CAPES).

\section{Referências}

1. Severo, N.C. Influência da qualidade do sêmen bovino congelado sobre a fertilidade. A Hora Veterinária, Jan-Fev, p.57-65, 2009

2. Bortolozzo, F.P.; Wentz, I.; Dallanora, D. Situação atual da inseminação artificial em suínos. Acta Scienficae Veterinariae, v.33, n.1, p.17-32, 2005.

3. Scheid, I.R. Transportando e armazenando corretamente as doses de sêmen. Suínos e Cia. v.2; p.25-31, 2003.

4. Watson, P.F. Cooling of spermatozoa and fertilizing capacity. Reproduction in Domestic Animals. v.31, n.1, p.135-140, 1996.

5. Figueiroa, P.T.B.; Salviano Neto, P.; Oliveira, R.R. et al. Avaliação da viabilidade do sêmen suíno submetido à refrigeração. Revista Brasileira de Reprodução Animal. v.25, p.442-445, 2001.

6. Nunes, J.F.; Salgueiro, C.C. de M. Utilização da água de coco como diluidor de sêmen de caprinos e ovinos. Revista Científica de Produção Animal. v.1, n.1, p.17-26, 1999.

7. Toniolli, R.; Jathay, P.C.; Silva, M.C.; Moreira, F.R. da C. Utilização do leite desnatado e do ácido 3-indol 
acético na conservação do sêmen suínos. Ciência Animal. v.11, n.1, p.21-26, 2001.

8. Cardoso, R. de C.S.; Silva, A.R.; Uchoa, D.C.; Silva, L.D.M. da. Criopreservação de sêmen canino com um diluidor à base de água de coco. Ciência Rural. v.32, n.4, p.657-661, 2002.

9. Meireles, L.S.; Malschitsky, E.; Neves, A.P.; Vieira, M.J.; Keller, A.; Hott, A.K.; Moraes, I.M.A. de; Garbade, P.; Gregory, R.M.; Mattos, R.C. Leite em pó desnatado não inativado e leite desnatado UHT para a preservação e fertilidade do sêmen equino resfriado. Ciência Rural. ; v.28, n.3, p.467-470, 1998.

10. Toniolli, R.; Toniollo, G.H.; Franceschini, P.H.; Morato, F.M.A.C.. Uso do diluente água de coco em pó $\left(\mathrm{ACP}-103^{\circledR}\right)$ na conservação prolongada do sêmen do varrão: avaliação in vitro e in vivo. Arquivos Brasileiros de Medicina Veterinária e Zootecnia. v.62, n.5, p.1072-1079, 2010.

11. Perez Garcia, T. Importancia de la tecnologia en la obténcion del semen bovino. Revista Patronal Biology Animal. v.4, p.249-257, 1958.

12. Toniolli, R.; Mesquita, D.S.M.; Cavalcante, S.G. Avaliação in vitro do sêmen de suíno diluído em BTS e na água de coco in natura e estabilizada. Revista Brasileira de Reprodução Animal. v.22, p.198-201, 1998.

13. Hancock, J.L.; Hovell, G.J.R. The collection of boar semen. Veterinary Record. v.71, p.664-665, 1959.

14. Toniolli, R. Pouvoir fecondant des spermatozoides $\underline{\mathrm{d} u}$ ) verrat: amèlioration des conditions de conservation. 91p, 1996. (Rabelais de Tours, France). These (Doctorat) Université François Rabelais de Tours. (Cópia da Tese na Biblioteca de Universidade Estadual do Ceará). Resumo disponível em < $<$ ttp://cat.inist. $\underline{\mathrm{fr} / \text { ?aModele}=\text { afficheN\&cpsidt }=182303}>$ Acesso em: 01/2012.

15. Martin Rillo, S.; Martinez, E.; Garcia Antiga, C.; De Alba, C. Boar semen evaluation in practise. Reproduction in Domestic Animals. v.31, p.519-526, 1996.

16. Salgueiro, C.C.M.; Nunes, J.F.; Oliveira, K.P.L. Utilização de diluentes á base de água de coco in natura e em pó, na inseminação artificial programada de cabras. Revista Brasileira de Reprodução Animal. sup.1, n.5, p.96-98, 2002.

17. Medeiros, A.A.; Araújo, A.A.; Moura, A.A.A.; Cavalcante, J.M.M.; Figueirêdo, E.L.; Rodrigues, L.F.S. Utilização do azul de bromofenol conservado a $4{ }^{\circ} \mathrm{C}$ e $29^{\circ} \mathrm{C}$, como método de coloração vital para a avaliação do espermatozoide ovino. Revista Ciência Agrária. v.46, p.287-297, 2006.

18. Smital, J. Effects influencing boar semen. Animal Reproduction Science. v.110, p.335-346, 2009.

19. Uchoa, D.C.; Silva, A.R.; Cardoso, R.de C.S.; Pereira, B.S.; Silva, L.D.M. Conservação do sêmen canino a $37^{\circ} \mathrm{C}$ em diluentes â base de água de coco. Ciência Rural. 2002; 32(1):91-95.

20. Medeiros, B. F. de. Avaliação de sêmen ovino refrigerado diluído em água de coco em pó. 29.p. Campina Grande, PB. Monografia (Graduação em Medicina Veterinária). Universidade Federal de Campina Grande, 2008. Disponivel em: <http://www.cstr.ufcg.edu.br/mono_mv_2008_2/monogr_bruno_fernandes.pdf $>$. Acesso em: 05/2012.

21. Rondon, R.M.M.; Rondon, F.C.M.; Nunes, J.F.; Alencar, A.A.; Sousa, F.M.; De \& Carvalho, M.A. M. Uso da água de coco em pó $\left(\mathrm{ACP}^{\circledR}\right)$ em diferentes temperaturas como diluente de espermatozóides de capote (Numida meleagris). Revista Brasileira de Saúde e Produção Animal. v.9, n.4, p.848-854, 2008.

22. Kulaksiz, R.; Çebi, Ç.; Akçay,E. The effect of different extenders on the motility and morphology of ram sperm frozen or stored at $4{ }^{\circ} \mathrm{C}$. Turk. Journal of Veterinary and Animal Science; v.36, n.2, p.177-182, 2012.

23. Barros, T.B.; Guimarães, D.B.; Cantanhêde, L.F.; Dias, A.V.; Souza, L.P.; Feugang, J.M.; Toniolli, R. The use of skimmed dried milk as na alternative diluente for the cooling step during the boar freezing procedure. Semina: Ciências Agrárias, v.36, n.3, supl.1, p.2023-2030, 2015.

24. Kasimanickam, R.; Kasimanickam, V.; Tibary, A.; Pelzer, K. Effect of semen extenders on sperm parameters of ram semen during liquid storage at $4{ }^{\circ} \mathrm{C}$. Small Ruminant Research, v.99, p.208-213, 2011.

25. Paquignon, M.; Bussière, J.; Bariteau, F. Efficacité des techniques de conservation de la semence de verrat. INRA - Prodution Animal, v.1, p.271-280, 1988.

26. Toniolli, R.; Barros, T.B.; Toniolli, L.S.; Guimarães, D.B.; Dias, A.V.1; Cantanhêde, L.F.; Araújo, L.R.S.1; Filho, I.B.Q. Qualidade espermática do ejaculado suíno conservado a $5{ }^{\circ} \mathrm{C}$ no diluente $\mathrm{ACP}-103^{\circledR}$ associado à 
gema de ovo. Ciência Animal, v.23, n.2, p.45-57, 2013.

27. Katzer, L.H.; Bernardi, M. L.; Bortolozzo, F.P.; Wentz, I. Qualidade de sêmen suíno resfriado soba influencia de diluentes, da temperatura de armazenamento e da incubação prévia. Ars Veterinaria, v.20, n.2, p.233-241, 2004.

28. Althouse, G.C.; Wilson, T.M M.E.; Kuster, C.; Parsley, M. Characterization of lower temperatures storage limitations of fresh-extended porcine semen. Theriogenology. v.50, p.535-543, 1998.

29. Kulaksiz, R.; Çebi, Ç.; Akçay, E. The effect of different extenders on the motility and morphology of ram sperm frozen or stored at $4{ }^{\circ} \mathrm{C}$. Turkie Journal of Veterinary and Animal Sciences; v.36, n.2, p.177-182, 2012.

30. Bartellier, F.; Duchamp, P.G.; Vidament, M.; Arnaud, G.; Palmer, E.; Masgistrini, M. Delayed insemination is successful with a new extender for storing fresh equine semen at $15^{\circ} \mathrm{C}$ under aerobic condictions. Theriogenology. v.50, p.229-236, 1998.

31. Garcia, M.A.; Graham, E.F. Dialysis of bovine semen and its effects on fresh and freeze - thawed spermatozoa. Cryobiology. v.24, p.446-454, 1987.

32. Estienne, M.J.; Harper, A.F.; Day, J.L.j Characteristics of sperm motility in boar sêmen diluted in diferente extenders and stored for seven days at 18 degrees C, Reproduction Biology. v.7, p.221-231, 2007.

33. Memon, M. A.; OTT, R. S. Methods of semen preservation and artificial insemination in sheep and goats. World Review of Animal Production. v.17, n.1, p.136-149, 1981.

34. Juliani, G.C.; Henry, M. Efeito do glicerol, etilenoglicol, acetamida e leite desnatado na criopreservação de espermatozoides equinos. Arquivos Brasileiros de Medicina Veterinária e Zootecnia. v.60, n.5, p.1103-1109, 2008. 